\title{
Development of Random Tree Based Student Competency Model in Java Programming
}

\author{
Devine Grace D. Funcion*
}

\author{
Leyte Normal University, Tacloban City, 6500 Leyte, Philippines; dgd_35@Inu.edu.ph
}

\begin{abstract}
Objective: Java programming is perceived to be a difficult subject. The educated programmer is in demand in the local and international market in creating computer application. However, no model that would assist the teacher in identifying the needed competency in Java programming that will make it less stressful for the student to understand the topic. Methods: data mining technique was explicitly utilized the random tree to predict the academic performance of the students. The purposeof gathering the data was through survey questionnaire for those fifty (50) are enrolled IT students in the IT_103 Java Programming subject answered and poll. Java Programming class schedules are: 10.30-12.00 MTh (Monday and Thursday), and 4.00-5.30 TFri (Tuesday and Friday). The researcher observed the schedule in conducting the survey. Findings: The algorithm generated by the decision tree model shows that conditional statement, operators, arrays and loops are important Java programming competency. It means that the student should learn mastery in the topics for them to become expert in java programming. Application/Improvements: In the formulation of the course syllabus for the Java Programming more contact hours should be given to the following topics conditional statement, Operators Arrays, and Loops for the student to understand more the problem. For more improvement of the subject area, theuse of another type of that the data mining technique is recommended and with additional parameters to test the accuracy in predicting Java competency.
\end{abstract}

Keywords: Array, Data Mining, Information Technology, Java Programming, Loops, Random Tree Algorithm

\section{Introduction}

In recent years, the demand for computer programmers has conveyed so much attention as it is one of the in-demand jobs in the local and international market. The Bureau of Labor and Statistics identified the fastest growing occupation projected until 2026 among the top is a software developer with one hundred eighty-six (1086.6) thousand employment needed $\stackrel{1}{\text {. Information }}$ Technology (IT) companies are hiring graduates who haveexcellent programming skills. Becoming a computer programmer requires great analytical thinking skills to design code and debug a program.

Moreover, analytical skills are necessary forproblemsolvingaccording to ${ }^{2}$ which involves identifying relevant information, assessing needs, determining available input, specifying desired objectives and results in the organization. In programming, there are two components (data, and instruction). To work with data, students need to understand variables and types; to work with instructions the student has to understand control structures and subroutines. Programming languages always have commands for getting data into and out of variables and for doing computations with data ${ }^{3}$. In the declaration, the object has a class which is composed of three members the field, method, and classes ${ }^{4}$. Moreover, skills such as computational thinking (problem-solving, complex systems design, evaluation, and understanding human behavior) are foundations of an IT professionals ${ }^{\underline{5}}$.

Java programming is an Object-Oriented Programming (OOP) tools to solve problems using class and object. Object-oriented programming as defined in webopedia a type of computer programming in which programmers applies not only the data structure but also the types of operations in data structure ${ }^{6}$. Also, OOP is a method of programming that involves the creation of an intellectual model that data is associated ${ }^{\mathrm{Z}}$. Java programming is the most popular programming language 
used in the world, and Java works in different platforms like in Windows, Mac, and Linux. Furthermore, Java programming is perceived to be a difficult subject of some IT student. The study of ${ }^{8}$ pointed out some reasons why Java programming is difficult for a student to learn. He identified three areas of programming difficulties; first multiple skills (syntax, structure, semantics, and style) other educational novelty (problem-solving and precision), and third variousprocesses (translation, algorithm, and coding).

However, with the high demand in computer programmer, there is scarcity in this field of profession. A report issued by the Commission on Higher Education (Ched) stated that in School Year 2016-2017 there are about 398,765 thousand students enrolled in the IT profession all over the Philippines. However, there are only 73,646 thousand total students who graduated in the S.Y 2016-2017 with the degree in Bachelor of Science in Information Technology ${ }^{9}$. Several kinds of literature show the reasons for the high turnout of IT dropouts. In the University of Tartu, Estonia in the school year 2014/2015,25\% of the students had dropped out in IT. Some of the reason identified was students indicated a math-related subject called discrete elements of math and programming to be too difficult $\underline{10}$.

Additionally, when coding specific programming language, it entails allotting of rules and processes to follow which makes programming challenging to learn. Another factor that influences the high dropout rate is a conflict of work while studying simultaneously ${ }^{11}$.

Additionally, reasons for the low turnout of IT graduates are student retention. According to ${ }^{12}$, the study of low retention has been prominent in programming subjects in tertiary level. Also, despite the popularity of high demand for computer programmer according to ${ }^{\frac{13}{3}}$ reason for low retention rate, student has a problem with the subject: learning how to program.

Another situation that makes programming challenging to learn are those students enrolled in none technological courses. In the K-12 program implemented by the Department of Education in the Philippines senior high school students can choose from the tracks such as Accounting, Business Management (ABM) track, Science, Technology, Engineering and Mathematics (STEM) track, Humanities and Social Science (HUMSS) track, and General Academic Strand (GAS) track. Moreover, those enrolled students in non-STEM track find it challenging to comprehend the topics in Java programming since computer programming is not part of the offeredsubject in the
non-STEM course.The Ched issued a Ched Memorandum Order (CMO 10) series of 2017 policy on student affected by the implementation of the K to 12 programs. The Higher Education Institution (HEIs) has the option to implement a bridging program to address the problem of some nonStEM courses who wish to take Information Technology course in the tertiary level to assist the student to understand the basic concepts of computer programming $\underline{14}$.

Several studies have been conducted to identify the competency of students in programming. In the study of ${ }^{15}$ he mentioned that student should develop more on the cognitive and metacognitive process, knowledge structures and, content representation. Another study of 16 the Evaluation of Programming Competency using Student Error Patterns he identified five (5) category of competency (Basic Programming, Sequencing, Tracing Non-iterative, Tracing Iterative, writing programs and Program Exception Handling). Students show that some problem and difficulty in error handling. It implies that competency in programming is essential so that IT students can create and solve real-world problem ${ }^{17}$.

Hence, the ability to predict competency in Java programming is essential to lessen the difficulty in programming. Moreover, data mining as a technique is employed in this study to discover new knowledge from a large amount of data to identify relationships such as patterns, the association among variable in databases. Discovery of knowledge can be examined using machine learning technique ${ }^{18}$. The study of student dropout rate in online education was conducted by ${ }^{19}$ and utilized data mining to predict reasons for dropout. A total of 189 students registered to the online Information Technologies Certificate Program in 2007-2009.The result of the research shows that online technologies self-efficacy, online learning readiness, and previous online experience as the most critical factors in predicting dropouts. The researcher deploys the used of random tree algorithm because of robustness in handling small datasets and numbers of fields. Also, the strength of the random tree is on classification and regression tree method. The random tree used two way of randomization first bagging, where it creates cloned training sets through sampling with replacement from the original datasets. Second, each split of the tree, is considered in a sampling of the input field for the impurity measure ${ }^{20}$.

Furthermore, data mining was conducted by ${ }^{21}$ employability of IT students in their on-job training as the result of the study Business Operation is the most critical attri- 
bute in the On-the-Job Training Wherein, students are trained to be productive, responsible and cooperative and have the initiative to act. Since computer programming is a difficult subject as stated in the literature. There are no studies conducted that will predict student competency in Java programming that will lessen the difficulty of programming among IT student. However, findings are limited to theoretical approaches. Furthermore, for the programming teachers to identify what specific lessons in Java programming that need more time in the discussion to help the student understand and become an expert in programming. Further, the research study is used to develop a model for predicting competency in Java programming.

\section{Methodology}

The study utilized Knowledge Discovery in Database (KDD) process which refers to the overall operation of discovering useful knowledge from data. Data mining is a particular step in this process-application of specific algorithms for extracting patterns (models) from data ${ }^{22}$. The objective is to unravel the hidden data behind the difficulty in learning computer programming and unleash the important competency necessary to improve the Java programming of the IT students. There is no other technique used to uncover hidden data except the KDD process.

\subsection{Data Mining Process}

\subsubsection{Data Collection}

The methodof gathering the data was through a survey questionnaire. A total of fifty (50) out of two hundred eight (208) first year IT students were identified to answer the survey questionnaire. The researcher observed the following class schedule in conducting the survey 10.30-12.00 MTh (Monday and Thursday) and 4.00-5.30 TFri (Tuesday and Friday). Table $1 \& 2$ show the rating and limit scale used to identify the level of competency in Java programming.

Table 1. Qualitative description for the level of competency in java programming

\begin{tabular}{|l|l|}
\hline Rating Scale & Qualitative Description \\
\hline 5 & Expert \\
\hline 4 & Advance \\
\hline 3 & Intermediate \\
\hline 2 & Newbie \\
\hline 1 & No Knowledge \\
\hline
\end{tabular}

Table 2. Limit scale and the qualitative description for the level of competency in java programming

\begin{tabular}{|l|l|}
\hline Frequency Distribution & Qualitative Description \\
\hline $4.21-5.00$ & Expert \\
\hline $3.41-4.20$ & Advance \\
\hline $2.61-3.40$ & Intermediate \\
\hline $1.81-2.60$ & Newbie \\
\hline $1-1.80$ & No Knowledge \\
\hline
\end{tabular}

\subsubsection{Data Sampling}

The researcher is handling two (2) Java Programming (IT_103) subject. In each subject a total of thirty-five (35) students. However, some students dropout and stop attending the classes during the conducting classes. Some students were absent during the conduct of the survey questionnaire. However according to the study of $\underline{23}$ having a relatively small microarray dataset $(n=53$ to 280) the predicted and actual classification error is between 1\%-7\%. Additionally, in small sample size, re-sampling strategies like the bootstrap ore repeated/ iterated $\mathrm{k}$-fold cross validation are a most appropriate tool to sample test $\underline{24}$.

\subsubsection{Software Used}

The Weka software was utilized to analyze the data. Weka is a machine learning algorithm and data processing. It provides extensive support for the whole process of experimental data mining, including preparing the input data, evaluating learning schemes statistically, and visualizing both the input data and the result of learning $\underline{25}$.

\subsubsection{Data Preparation and Processing}

During this phase, a pre-processing of collected and prepared the data for the mining techniques. At first, we eliminated some irrelevant attributes, e.g., student name, Student Track, teacher's name, and schedule. Then, each survey report will have the following characteristics as shown in Table 3. 
Table 3. Sample datasets

\begin{tabular}{|c|c|c|c|c|c|c|}
\hline Basic in Java Programming & Operators & Conditional Statement & Loops & Array & Mean & Remarks \\
\hline 3 & 2 & 3 & 1 & 1 & 2.0 & Newbie \\
\hline 3 & 3 & 3 & 3 & 1 & 2.6 & Newbie \\
\hline 3 & 3 & 3 & 2 & 2 & 2.6 & Newbie \\
\hline 3 & 3 & 3 & 3 & 2 & 2.8 & Intermediate \\
\hline 3 & 3 & 3 & 3 & 2 & 2.8 & Intermediate \\
\hline 3 & 3 & 3 & 2 & 2 & 2.6 & Intermediate \\
\hline 3 & 3 & 3 & 3 & 2 & 2.8 & Intermediate \\
\hline 4 & 3 & 4 & 3 & 1 & 3.0 & Intermediate \\
\hline
\end{tabular}

Second step data preparation, the result of the survey was in MS Excel and later converted to Microsoft Excel Comma Separated Values File (.csv). The .csv file was then loaded to Notepad ${ }^{++}$. In this stage, data cleaning is done to eliminate unwanted symbols (i.e., comma, colon, spaces).

Additionally,in the notepad application declaration of syntaxes like@Relation, @Attribute, and @Datais included as a requirement in the Weka application. The convertedtext file to Attribute-Relation File Format (ARFF) in notepad describes the list of instances sharing a set of attributes and the accepted file format for WEKA application. Next, information is uploaded to the Weka Application and conducted the pre-processing of raw data to a more understandable file format. The third step, data modeling, in WEKA it utilized the Random Tree algorithm to predict competency in Java programming.

\subsubsection{Data Visualization}

After loading the data to WEKA, we set out some primary useful knowledge about the attributes before applying any data mining method by using the visualizing technique in the software. For example, we found that in the Remarks attribute there are eight (8) student shows basic programming competency in java programming, eleven (11) students under operator's competency, and twenty-five (25) students under conditional statement competency, four (4) students under Loops competency, one (1) students under Array competency. The problem is how what specific competency in Java programming does the teacher will give more emphasis to improve the level of competency among BSIT Fist year students.

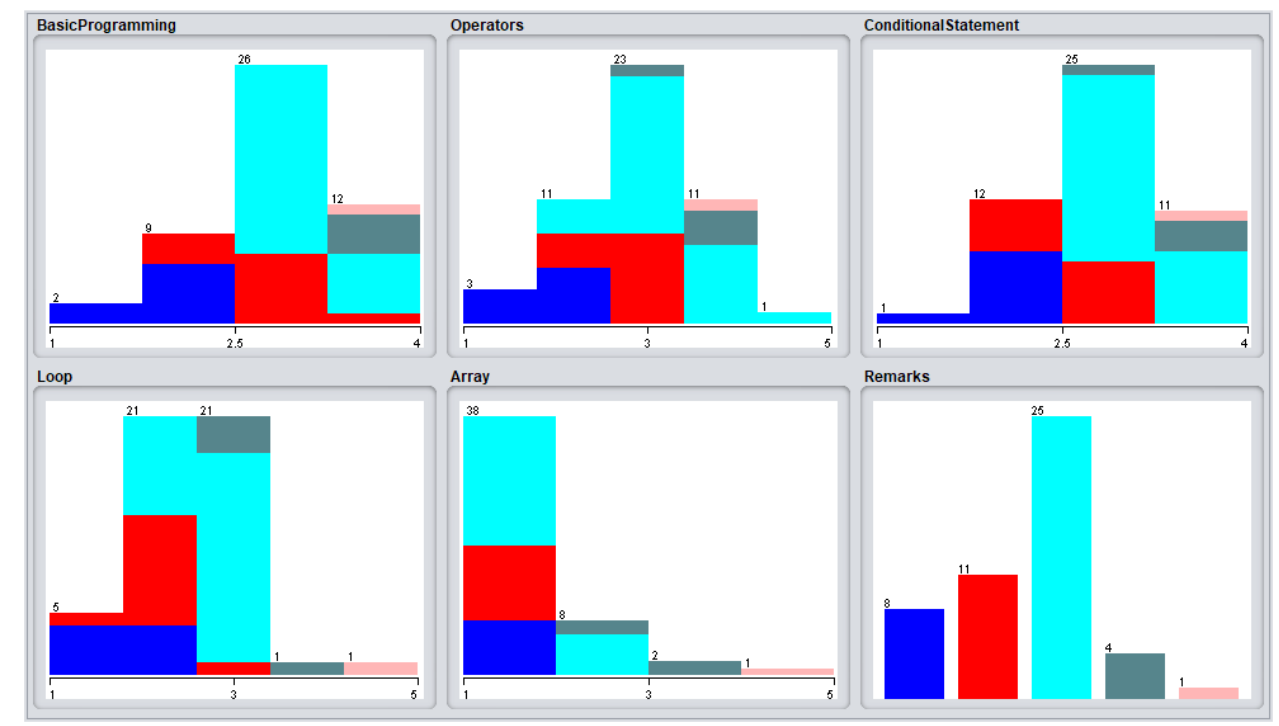

Figure 1. Primary visualization of the different attributes. 


\subsubsection{Random Tree Algorithm}

A random tree is a rooted tree following the Markov process. The nodes in a random tree with the arrays of the $\mathrm{n}$-dirnensiona. 1 vectors are associated. The identified random tree can be a collection of vector $\operatorname{arrays} \underline{26}, 27$.

$$
\{S_{0}, S_{1}[b], \ldots \ldots, S_{N} \overbrace{[b] \ldots .[b]}^{N}\}
$$

Costs of $\mathrm{n}$ properties at time $\mathrm{k} \Delta \mathrm{t}$ are enclosed inside $\mathrm{n}$-dimensional vector $\{\operatorname{Sk}[\mathrm{i} 1] \ldots[\mathrm{ik}] \mid \mathrm{i} 1, \ldots, \mathrm{ik}=1, \ldots, \mathrm{b}\}$. All nodes have the same number of branches, b. All branches have direction, showing time transition. The node at the branch head from the tailnode is originating. Initial vector $\mathrm{S} 0$, connected to the root, has an initial cost of $n$ properties.

For given kth vector, $S[i] \ldots[i]=(S[i] \ldots[i](j))$ $(1, \ldots) ,1 \mathrm{nk} 1 \mathrm{kk} 1 \mathrm{kj}=1 \mathrm{iK}+=\mathrm{b}$ is created.

$$
R(t+\Delta t)=\exp \left[\begin{array}{l}
\Delta t\left(r I-\operatorname{diag}\left(\delta_{1}+\sigma_{1}^{2} / 2, \ldots, \delta_{n}+\sigma_{1}^{2} / 2\right)\right)+ \\
\left.\sqrt{\Delta t} \operatorname{diag}\left(\sigma_{1} W_{1}(t), \ldots, \sigma_{1} W_{n}(t)\right)\right]
\end{array}\right] R(t)
$$

Condition is $\mathrm{S}(\mathrm{k} \Delta \mathrm{t})=\mathrm{Sk}[\mathrm{i} 1] \ldots[\mathrm{ik}]$ at time $\mathrm{k} \Delta \mathrm{t} \mathrm{t}^{26}, 27$

$$
\begin{aligned}
& S_{k+1}\left[i_{1}\right] \ldots\left[i_{k}\right][i](j)= \\
& \left.S_{(k)}\left[i_{1}\right] \ldots\left[i_{k}\right](j) \exp \left[r-\delta_{j}-\sigma_{j}^{2} / 2\right) \Delta t+\sigma_{j} \sqrt{\Delta t} W_{i}(j)\right]
\end{aligned}
$$

Random Decision Trees algorithm was shown to have nearly comparable accuracy to Random Forest but without using bootstrap samples based on the training set. The critical advantage of completely random trees for our experiment is that growing the trees does not depend on the training data, which means that a single forest can be generated once and used for case bases with different sets of case instances ${ }^{28}$.

\section{Result and Discussion}

Figure 2 illustrates the graphical presentation of the pruned decision tree of Student Competency in Java Programming. Hence, the major topic in Java programming covers (Basic Programming, Operators, Conditional Statement, Loops, and Arrays). Wherein, Conditional Statement as the highest instances and become the first split between the (Operators $<=2.5$ ) and (Array $>2.560$ ) in predicting student competency in java programming.

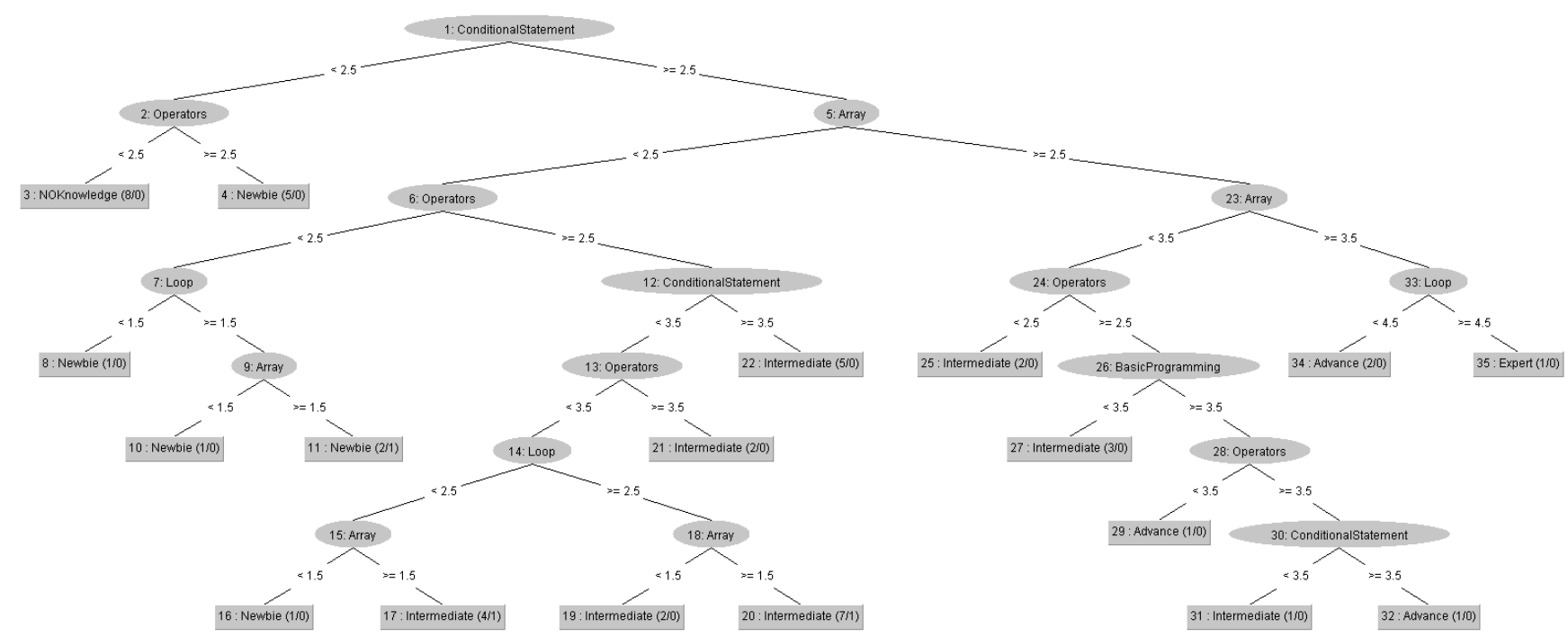

Figure 2. Decision tree of student competency model in java programming.

Table 4 shows the correctly classified instances wherein there are $77.55 \%$ precisely classified instances and $22.44 \%$ incorrectly individual instances this is supported by Table 5 that shows the complete accuracy by class wherein the Precision Weight Average of the competency level of student in Java programming is $78.10 \%$.
It implies that the conditional statement having a weighted average of $78.10 \%$ is an important attribute or topic in Java programming that the teacher needs to focus more attention during class discussion. Giving more computer programming problems and activities should be implemented in the use of conditional statements, 
operator and arrays. The more activities are provided to the students to analyze the computer programming problem the higher the probability the student will be able to understand and find the subject not challenging to understand. In the study, of ${ }^{29}$ ten quick tips for teaching programming, he mentioned the best way to guide the student in programming use worked examples: a step-bystep guide in solving an existing programming problem. The instructor provides many similar programming examples for learning purposes. Worked samples should be broken down into sub-goals and labels. Predicting student competency in Java programming is essential to reduce the difficulty in understanding Java programming. Hence, to enhance the learning in a conditional statement, arrays, operators' teachers may conduct scaffolding, coaching, and modeling to help students master intellectually challenging operations. The model should address 'orientation' by incorporating a right introductory section on programming, and its different types ${ }^{30}$.

Table 4. Correctly classified instances

\begin{tabular}{|l|l|l|}
\hline $\begin{array}{l}\text { Correctly Classified } \\
\text { Instances }\end{array}$ & 38 & $77.551 \%$ \\
\hline $\begin{array}{l}\text { Incorrectly Classified } \\
\text { Instances }\end{array}$ & 11 & $22.449 \%$ \\
\hline Kappa statistic & 0.6482 & \\
\hline Mean absolute error & 0.1061 & \\
\hline Root mean squared error & 0.3079 & \\
\hline Relative absolute error & $39.3793 \%$ & \\
\hline $\begin{array}{l}\text { Root relative squared } \\
\text { error }\end{array}$ & $84.4445 \%$ & \\
\hline $\begin{array}{l}\text { Total Number of } \\
\text { Instances }\end{array}$ & $\mathbf{4 9}$ & \\
\hline
\end{tabular}

Table 5. Detailed accuracy by class

\begin{tabular}{|c|c|c|c|c|c|c|}
\hline & $\begin{array}{r}\text { TP } \\
\text { Rate }\end{array}$ & $\begin{array}{c}\text { FP } \\
\text { Rate }\end{array}$ & Precision & Recall & MCC & Class \\
\hline & 1 & 0 & 1 & 1 & 1 & $\begin{array}{c}\text { NO } \\
\text { Knowledge }\end{array}$ \\
\hline & 0.636 & 0.026 & 0.875 & 0.636 & 0.689 & Newbie \\
\hline & 0.88 & 0.25 & 0.786 & 0.88 & 0.636 & Intermediate \\
\hline & 0.25 & 0.067 & 0.25 & 0.25 & 0.183 & Advance \\
\hline & 0 & 0.021 & 0 & 0 & -0.021 & Expert \\
\hline $\begin{array}{c}\text { Weighted } \\
\text { Avg. }\end{array}$ & $\mathbf{0 . 7 7 6}$ & $\mathbf{0 . 1 3 9}$ & $\mathbf{0 . 7 8 1}$ & $\mathbf{0 . 7 7 6}$ & $\mathbf{0 . 6 5 7}$ & \\
\hline
\end{tabular}

A Conditional Statement is statements that execute specific conditions whether the statement is 'True' or 'False'. In Java, there are two forms of conditional statements: the if-else statement, canchoose between two alternatives; the switch statement, to choose between multipleoptions.The basic structure of an If-Else Statement follows this structure;

$$
\begin{aligned}
& \text { if (expression) }\{ \\
& \} \quad / / \text { codes } \\
& \text { else (expression) }\{ \\
& \quad / / \text { codes } \\
& \}
\end{aligned}
$$

While operators are a symbol used to perform operations of addition, subtraction, division multiplication and even comparing values using the greater-than-equal symbol, less-than-equal symbol.

$$
\begin{aligned}
& \begin{array}{l}
\text { if (age < }=18)\{ \\
\text { system.out.println( ("You are underage"); }
\end{array} \\
& \text { else \{ } \\
& \}
\end{aligned}
$$

The above Java code will determine the age of the person. If the statement is true, then personage is Under Age, hence if the statement is false, then the personage is his at legal age. Observe in the above code conditional statement and operators are connected or intertwined if the student does not know how to construct correct conditional statement and use correct operations then the struggle is present. According to the study ${ }^{31}$ student ability to provide semantically correct code hinders their ability to recall and apply correct syntax.

\section{Conclusion}

Predicting student competency in java programming using random tree algorithm is helpful for the student who is facing difficulty in Java programming. Hence, for the student to become an expert in programming topics like a conditional statement operators, arrays, and loops are programming skills or competencies that need to have mastery from the student. Also, for the teachers handling programming subject, these will serve as guide and awareness of the topics in Java programming that needs more time and attention more complete activities and exercises that will enhance more there cognitive thinking and rea- 
soning during class discussion to give more emphasis on the importance Java programming.

\section{Recommendation}

The following are some recommendations:

1. In the formulation of the course syllabus for the Java Programming, more contact hours should be given to the following topics conditional statement, operators arrays, and loops for the student to understand more the problem and become an expert in Java programming,

2. Other State, Colleges, and Universities might consider the topics in a conditional statement, operators loop and array as essential skills in Java programming that the IT student must understand,

3. Bridging program be conducted to equipped students with basic knowledge in $\mathrm{C}$ programming as lowlevel and structured programming to the non-STEM course,

4. During class discussion, teachers should not focus more on the theoretical components of the subject but more on the practical application of the topics in java programming. It is recommended to give more programming activities to the student's to help the student recall the syntax is used in Java programming, and

5. More comprehensiveconduct of research study in the use of Random Tree in predicting student competency in Java programming to havea more accurate result.

\section{Reference}

1. Bureau of Labor Statistics (2018). Fastest Growing Occupations. United States Department of Labor. Retrieved from https://www.bls.gov/emp/tables/fastest-growingoccupations.htm.

2. Dalbey J, and Linn MC. (1985). The demands and requirements of computer programming: A literature review, Journal of Educational Computing Research. 1(3):253-74. https://doi.org/10.2190/BC76-8479-YM0X-7FUA.

3. David J Eck. Introduction to programming using java. Department of Mathematics and Computer Science Hobart and William Smith Colleges Geneva, NY; 2006. https://book.huihoo.com/introduction-to-programmingusing-java-fifth-edition/.

4. Arnold K, Gosling J. and Holmes D. (2005). The Java programming language, 4th Ed. Addison Wesley Professional; 928p. ISBN: 0-321-34980-6. etf.beastweb.org/index.php/site/ download/Java_Programming.pdf.

5. Giannakos MN, Aalberg T, Divitini M, Jaccheri L, Mikalef P, Pappas I and Sindre G. (2017). Identifying dropout factors in information technology education: A case study. In: Global Engineering Education Conference (EDUCON); 2017. p. 1187-94. https://doi.org/10.1109/ EDUCON.2017.7942999.

6. Beal Vangie (2019). OOP - Object Oriented Programming. Retrieve from https://www.webopedia.com/TERM/O/ object_oriented_programming_OOP.html.

7. Kendal S. (2009). Object Oriented Programming using Java, Bookboon. Retrieve from: http://zodml.org/sites/default/ Object_Oriented_Prograamming_1. using_Java_0.pdf.

8. Adair D and Jaeger M. (2011). Difficulties in teaching and learning the Java programming language. In: Proceedings of the 17th International Conference on Engineering Education; p. 21-26.

9. Commission on Higher Education (2018). Higher Education Graduates by Discipline Group: AY 200607 to AY 2016-17. Retrieve from: https://ched.gov. $\mathrm{ph} / \mathrm{wp}$-content/uploads/2018/07/Higher-EducationGraduates-by-Discipline.pdf.

10. Altin H and Rantsus R. (2015). Why students fail to graduate ICT-related curricula at university level, INTED2015 Proceedings. 5364-68.

11. Kori K, Altin H, Pedaste M, Palts T and Tõnisson E. (2014). What influences students to study information and communication technology, INTED2014 Proceedings. 1477-86.

12. Bennedsen J and Caspersen ME. (2007). Failure rates in introductory programming, ACM SIGcSE Bulletin. 39(2):32-36. https://doi.org/10.1145/1272848.1272879.

13. Begosso LC, Begosso LR, Gonçalves EM and Gonçalves JR. (2012, October). An approach for teaching algorithms and computer programming using Greenfoot and Python. In: Frontiers in Education Conference (FIE), IEEE; p. 1-6. https://doi.org/10.1109/FIE.2012.6462307.

14. Commission on Higher Education (2017). CHED CMO no.10 s.2017. Policy on Student Affected by the Implementation of the K - 12 Program and the New General Education Curriculum. Retrieved from: https://ched.gov. ph/wp-content/uploads/2017/10/CMO-10-s-2017.pdf.

15. Kramer M, Hubwieser P and Brinda T. (2016, March). A competency structure model of object-oriented programming. In: Learning and Teaching in Computing and Engineering (LaTICE), 2016 International Conference, IEEE; p. 1-8. https://doi.org/10.1109/LaTiCE.2016.24.

16. Kiran EL and Moudgalya KM. (2015, April). Evaluation of programming competency using student error patterns. In: Learning and Teaching in Computing and Engineering 
(LaTiCE), 2015 International Conference, IEEE; p. 34-41. https://doi.org/10.1109/LaTiCE.2015.16.

17. Zorba E. (2011). Identifying the computer competency levels of recreation department undergraduates, Turkish Online Journal of Educational Technology-TOJET. 10(4):211-20.

18. Pal S. (2012). Mining educational data to reduce dropout rates of engineering students, International Journal of Information Engineering and Electronic Business. 4(2):1. https://doi.org/10.5815/ijieeb.2012.02.01.

19. Yukselturk E, Ozekes S and Türel YK. (2014). Predicting dropout student: An application of data mining methods in an online education program, European Journal of Open, Distance and E-learning. 17(1):118-33. https://doi. org/10.2478/eurodl-2014-0008.

20. Ajay Kumar Mishra, Bikram Kesari Ratha (2016). Study of random tree and random Forest data mining algorithms for microarray data analysis|, International Journal on Advance Electrical and Computer Engineering (IJAECE). 3(4). ISSN (Print): 2349-932X.

21. Verecio RL. (2018). Predicting employability skills among information technology graduates of Philippine State University in their on-the-job training using J48 algorithm, Indian Journal of Science and Technology. 11(37).

22. Fayyad U, Piatetsky-Shapiro G and Smyth P. (1996). The KDD process for extracting useful knowledge from volumes of data, Communications of the ACM. 39(11):27-34. https://doi.org/10.1145/240455.240464.

23. Figueroa RL, Zeng-Treitler Q, Kandula S and Ngo LH. (2012). Predicting sample size required for classification performance, BMC Medical Informatics and Decision Making. 12(1):8. https://doi.org/10.1186/1472-6947-12-8. PMid: 22336388, PMCid: PMC3307431.

24. Beleites C, Neugebauer U, Bocklitz T, Krafft C and Popp J. (2013). Sample size planning for classification models, Analytica Chimica Acta. 760:25-33. https://doi.org/10.1016/j.aca.2012.11.007. PMid: 23265730.
25. Frank E, Hall M, Holmes G, Kirkby R, Pfahringer B, Witten IH and Trigg L. (2009). Weka-a machine learning workbench for data mining. In: Data Mining and Knowledge Discovery Handbook, Springer, Boston, MA; p. 1269-77. https://doi.org/10.1007/978-0-387-09823-4_66.

26. Alickovic E and Subasi A. (2013, May). Comparison of decision tree methods for breast cancer diagnosis. In: The 6th International Conference on Information Technology (ICIT 2013), Amman, Jordan. https://www.researchgate. net/publication/259070804_Comparison_of_decision_ tree_methods_for_breast_cancer_diagnosis.

27. Morohosi H and Fushimi M. (2002). Quasirandom tree method for pricing American style derivatives, Special issue on theory, methodology and applications in financial engineering, Journal of the Operations Research Society of Japan. 45(4):426-34. https://doi.org/10.15807/jorsj.45.426.

28. Houeland TG. (2011, March). An Efficient Random Decision Tree Algorithm for Case-Based Reasoning Systems. In: Proceedings of the Twenty-Fourth International Florida Artificial Intelligence Research Society Conference. p. 197-204. ISBN: 978-3-642-21221-5. https://dl.acm.org/ citation.cfm? $\mathrm{id}=2021531$.

29. Brown NCC, Wilson G. (2018). Ten quick tips for teaching programming, PLoS Comput. Biol. 14(4):e1006023. Retrieve from https://journals.plos.org/ploscompbiol/ article?id=10.1371/journal.pcbi. 1006023 .

30. Mow IC. (2012). Analyses of student programming errors in Java programming courses, Journal of Emerging Trends in Computing and Information Sciences. 3(5):739-49.

31. Öqvist M and Nouri J. (2018). Coding by hand or on the computer? Evaluating the effect of assessment mode on performance of students learning programming, Journal of Computers in Education. 5(2):199-219. https://doi. org/10.1007/s40692-018-0103-3. 